MINI-SYMPOSIUM

\title{
Indications and optimal timing for surgery in infective endocarditis
}

\author{
F Delahaye, M Célard, O Roth, G de Gevigney
}

Heart 2004;90:618-620. doi: 10.1136/hrt.2003.029967

M ore and more patients are operated on during the active phase of infective endocarditis (IE). ${ }^{1}$ Between 1991 and 1999, in France, the rate of cardiac surgery has increased from $31 \%$ to $50 \%{ }^{1}$ This may, at least in part, explain the concomitant decrease of in hospital mortality, from $22 \%$ to $17 \% .^{1}$ Nonetheless, the indications for cardiac surgery and its optimal timing remain difficult decisions.

The principal indications for cardiac surgery are heart failure, no control of infection, embolisms, large size of vegetations, severe valvar and perivalvar lesions, and infection caused by some microorganisms.

\section{INDICATIONS FOR CARDIAC SURGERY Heart failure}

If heart failure is present, the mortality rate of native valve infective endocarditis is $55-85 \%$ in the case of medical treatment only and $10-35 \%$ in operated patients. ${ }^{2}$

The first indication for cardiac surgery in infective endocarditis is heart failure: it represents more than half of the indications. Heart failure caused by aortic regurgitation is particularly poorly tolerated (heart failure is better tolerated in the case of mitral regurgitation because the left atrium and the pulmonary vascular bed adapt better than the left ventricle to the regurgitant volume), and it progresses faster, thus needing rapid surgery.

Not only does heart failure increase the mortality rate if there is no surgery, but it also increases the perioperative mortality rate: from $5-10 \%$ in patients without heart failure to $15-35 \%$ in patients with heart failure. Moreover, delaying surgery increases the risk of perivalvar infection.

\section{No control of infection}

The first step is to make sure that there is no extracardiac infectious location. If there is no such extracardiac location, cardiac surgery should be performed if the course of fever and inflammatory syndrome is unfavourable after one week of appropriate antibiotic treatment.

\footnotetext{
Vegetations and embolic risk

The literature on this topic contrasts greatly. The embolism rate varies from $10-50 \%$ in different series. ${ }^{3}$ Three quarters of embolisms occur before the beginning of antibiotic treatment. ${ }^{4}$ The embolic risk decreases greatly and regularly over time, from $15 \%$ after one week of treatment to $1 \%$ after four weeks of treatment. ${ }^{5}$ In mitral infective endocarditis, embolisms look to be more frequent if vegetations are located on the anterior leaflet than on the posterior leaflet. ${ }^{6}$ Embolisms are more frequent when vegetation size is more than $20 \mathrm{~mm}$ in some studies, but not in other studies. ${ }^{2}$ In a recent study, embolisms were more frequent when the size of the vegetations was more than $10 \mathrm{~mm}$ or when vegetations were very mobile. ${ }^{3}$

Embolisms should always be looked for not only by clinical means but also by systematic scanners (for example, cerebral, thoraco-abdominal), searching for clinically silent embolisms, especially in spleen and kidneys.
}

Rapid surgery must be performed when there has been an embolic episode and when large and mobile vegetations remain. When there are large and/or mobile vegetations but no embolic event, the medical community is divided. The decision is easier in the case of mitral infective endocarditis when valve repair looks possible, or when there are other arguments for surgery (heart failure, no control of infection, severe valvar and perivalvar lesions, etc).

\section{Perivalvar infection}

Infective endocarditis on the aortic valve and prosthetic infective endocarditis are those most commonly associated with perivalvar infection, such as abscesses and intracardiac fistula: $10-40 \%$ of aortic valve infective endocarditis and 45 $100 \%$ of prosthetic infective endocarditis. ${ }^{7}$ Occurrence and persistence of conduction disturbances are not very sensitive indicators of perivalvar infection, but they look very specific $(85 \%-90 \%){ }^{8}$

Rapid surgery is recommended in most cases since the perioperative risk increases with the delay to surgery. ${ }^{8}$ ? However, in large aortic abscesses, a large resection exposes the patient to the risk of postoperative complete atrioventricular block.

\section{Valvar obstruction}

Valvar obstruction is an obvious indication for urgent surgery.

\section{Unstable prosthesis}

Dehiscence of an infected prosthesis means that there is perivalvar infection, and haemodynamic deterioration usually occurs quickly. Thus rapid surgery is recommended. ${ }^{2}$

\section{Prosthetic infective endocarditis}

In early prosthetic infective endocarditis $(<12$ months after valve replacement), most often the microorganism is a Staphylococcus and lesions are severe (abscess, prosthesis dehiscence). ${ }^{10}$ Redo surgery is associated with a lower mortality rate than medical treatment alone, and it is most often necessary, although it may be technically difficult. ${ }^{11}$

The mortality rate of prosthetic infective endocarditis caused by Staphylococcus aureus is about $75 \%$ in the case of medical treatment and $25 \%$ in the case of medical + surgical treatment. ${ }^{12}$ In a multivariate analysis in a study including 33 patients, the risk of death was 14 times higher if there was an intracardiac complication, and it was 20 times lower in operated patients than in non-operated patients. ${ }^{12}$ Surgery is thus recommended in prosthetic infective endocarditis caused by $S$ aureus when there is an intracardiac complication.

Medical treatment only may be sufficient in cases of late infective endocarditis caused by some microorganisms (oral streptococci, organisms from the HACEK groupHaemophilus species, Actinobacillus actinomycetemcomitans, 
Table 1 Indications for surgery in patients with infective endocarditis ${ }^{2}$

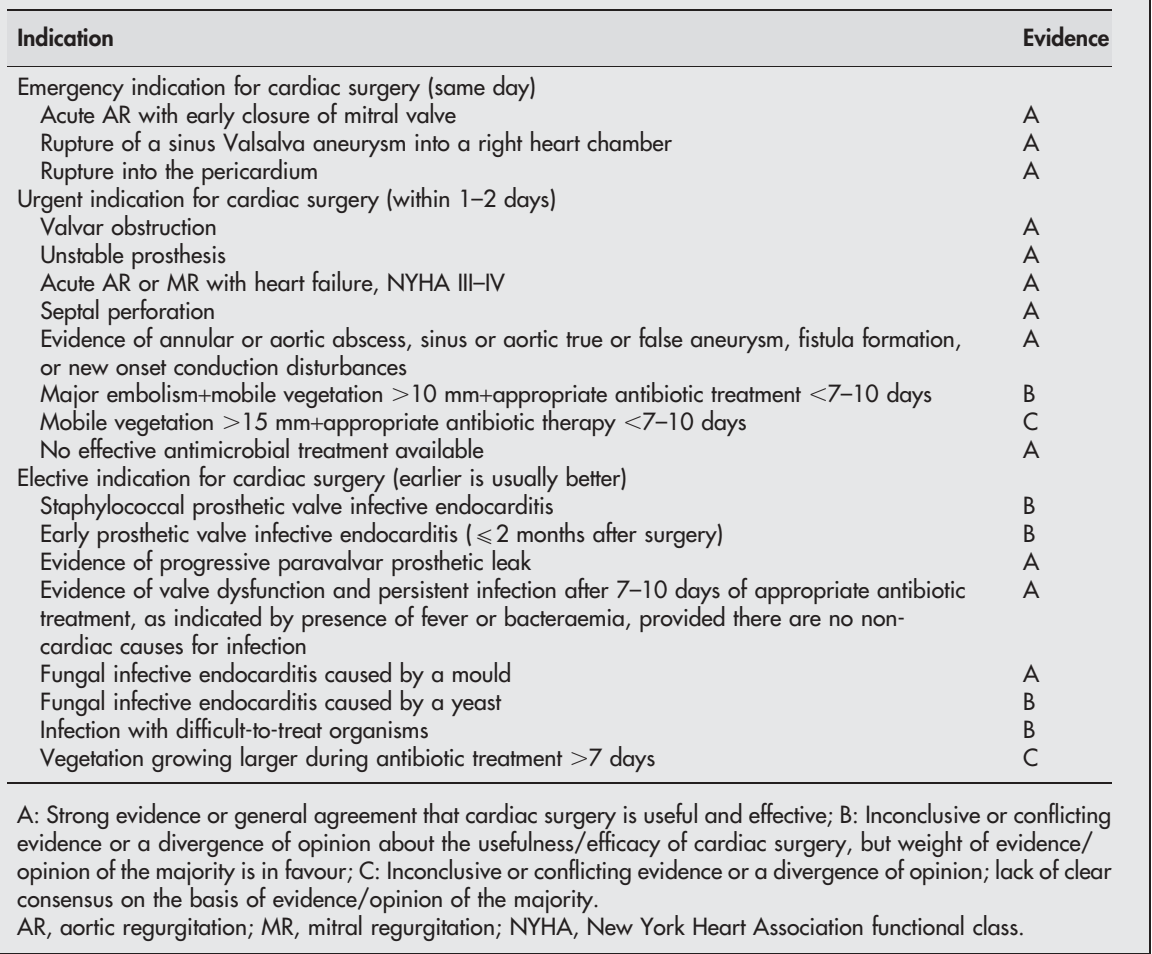

Cardiobacterium hominis, Eikenella corrodens, and Kingella kingae), if there are no signs of perivalvar infection. ${ }^{13}$

\section{Fungal infective endocarditis}

Infective endocarditis caused by Candida or Aspergillus are often complicated with very large vegetations, infectious metastases, perivalvar infection, and embolisms. ${ }^{14}$ Amphotericin B poorly penetrates into vegetations. Rapid surgery is thus most often needed.

\section{Difficult-to-treat microorganisms}

Surgery is almost always needed in infective endocarditis caused by certain Gram negative bacilli (for example, Pseudomonas aeruginosa, Achromobacter xylosoxitans), by Brucella, or by highly resistant enterococci.

\section{Neurological complications}

The rate of neurological complications varies from 15\% to $45 \%$ in different series. ${ }^{3}$ They mostly are ischaemic cerebral vascular accidents, but also cerebral haemorrhages, ruptured mycotic aneurysms, meningitis, and encephalopathy.

A cerebral scan must always be performed in infective endocarditis, to look for silent cerebral vascular accidents. In the case of cerebral haemorrhage, an arteriography or an angio-magnetic resonance image must be performed, to look for a mycotic aneurysm.

There is a risk of cerebral haemorrhage associated with cardiac surgery because of anticoagulation during and after the procedure. The risk of cerebral haemorrhage is not increased in the case of a stroke without haemorrhage, but it is greatly increased if the stroke is haemorrhagic. In this case, cardiac surgery should be delayed 2-3 weeks. ${ }^{15}$

If there is a ruptured mycotic aneurysm, it must be resected, clipped or embolised before cardiac surgery. ${ }^{15}$

\section{TIMING OF CARDIAC SURGERY}

Classically, early surgery was considered to be a greater risk than delayed surgery because of tissue inflammation and the surgery was technically more difficult. In fact, the duration of antibiotic treatment before surgery does not appear to influence the perioperative mortality, nor the rate of recurrent infective endocarditis. ${ }^{2} 1016$

Surgery should be rapid in the case of haemodynamic deterioration, where there is no control of infection, or there are large and mobile vegetations. Decision as to the timing of surgery is particularly difficult when there is a neurological complication.

\section{CONCLUSION}

Table 1 presents a summary of the indications for surgery and its timing, as proposed recently by Olaison and Pettersson. ${ }^{2}$

Indications for surgery and its timing are difficult decisions to reach. The patient must be followed up closely (clinical examinations once or twice a day, regular scans, and transthoracic and transoesophageal echocardiography). There must be close collaboration between the physician, the cardiac surgeon, and the microbiologist.

\section{Authors' affiliations \\ F Delahaye, M Célard, O Roth, G de Gevigney, Hôpital \\ cardiovasculaire et pneumologique, Lyon, France}

Correspondence to: Professor François Delahaye, Hôpital cardiovasculaire et pneumologique, BP Lyon Montchat, 69394-Lyon Cedex 03, France; francois.delahaye @ chu-lyon.fr

\section{REFERENCES}

1 Hoen B, Alla F, Selton-Suty C, et al. for the AEPEI group. Changing profile of infective endocarditis. Results of a 1-year survey in France. JAMA 2002;288:75-81.

2 Olaison L, Pettersson G. Current best practices and guidelines indications for surgical intervention in infective endocarditis. Infect Dis Clin North Am 2002;16:453-75

3 Di Salvo G, Habib G, Pergola V, et al. Echocardiography predicts embolic events in infective endocarditis. J Am Coll Cardiol 2001;37:1069-76.

4 Heiro M, Nikoskelainen J, Engblom E, et al. Neurologic manifestations of infective endocarditis: a 17-year experience in a teaching hospital in Finland. Arch Intern Med 2000; 160:2781-7. 
5 Alestig K, Hogevik H, Olaison L. Infective endocarditis: a diagnostic and therapeutic challenge for the new millennium. Scand J Infect Dis 2000;32:343-56.

6 Rohmann S, Erbel R, Gorge G, et al. Clinical relevance of vegetation localization by transoesophageal echocardiography in infective endocarditis. Eur Heart J 1992;13:446-52.

7 Choussat R, Thomas D, Isnard R, et al. Perivalvular abscesses associated with endocarditis: clinical features and prognostic factors of overall survival in a series of 233 cases. Perivalvular abscesses French multicentre study. Eur Heart J 1999:20:232-41.

8 Blumberg EA, Karalis DA, Chandrasekaran K, et al. Endocarditis-associated paravalvular abscesses. Do clinical parameters predict the presence of abscess? Chest 1995; 107:898-903

9 Knosalla C, Weng Y, Yankah AC, et al. Surgical treatment of active infective aortic valve endocarditis with associated periannular abscess. 11 year results. Eur Heart J 2000;21:490-7.

10 Chastre J, Trouillet JL. Early infective endocarditis on prosthetic valves. Eur Heart J 1995; 16(suppl B):32-8.
11 Gordon SM, Serkey JM, Longworth DL, et al. Early onset prosthetic valve endocarditis: the Cleveland Clinic experience 1992-1997. Ann Thorac Surg 2000;69: 1388-92

12 John MD, Hibberd PL, Karchmer AW, et al. Staphylococcus aureus prosthetic valve endocarditis: optimal management and risk factors for death. Clin Infect Dis 1998;26:1302-9.

13 Truninger K, Attenhofer Jost $\mathrm{CH}$, et al. Long term follow up of prosthetic valve endocarditis: what characteristics identify patients who were treated successfully with antibiotics alone? Heart 1999;82 714-20.

14 Moyer D, Edwards JE. Fungal endocarditis. In: Kaye D, ed. Infective endocarditis. New York: Raven Press, 1992:299-312.

15 Gillinov AM, Shah RV, Curtis WE, et al. Valve replacement in patients with endocarditis and acute neurologic deficit. Ann Thorac Surg $1996 \cdot 61: 1125-30$

16 D'Udekem Y, David TE, Feindel CM, et al. Long-term results of surgery for active infective endocarditis. Eur $J$ Cardiothorac Surg 1997;11:46-52.

\section{IMAGES IN CARDIOLOGY}

Mitral and tricuspid valve thrombus in antiphospholipid syndrome

A 58 year old woman with a one year history of antiphospholipid syndrome and ineffective anticoagulant treatment (international normalised ratio 1.2) was admitted with pain in the left hypochondrium. Abdominal ultrasound revealed a $5 \mathrm{~cm}$ wide splenic infarction. Transoesophageal echocardiography showed mobile masses resembling bunches of grapes on both the mitral and the tricuspid valves (panels $\mathrm{A}$ and $\mathrm{B}$, and video 1 - to view video footage go to http://www.heartjnl.com/supplemental). On control transoesophageal echocardiography after six weeks of effective anticoagulation, these masses almost entirely disappeared from both valves (panel $\mathrm{C}$ and video 2 ). The patient showed no signs or symptoms of embolism during the same period.

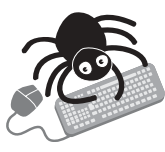

Video footage appears on the Heart website-http:// www.heartjnl.com/supplemental

J Tomcsányi, A Zsoldos, M Szabó tomcsanyi.janos@axelero.hu
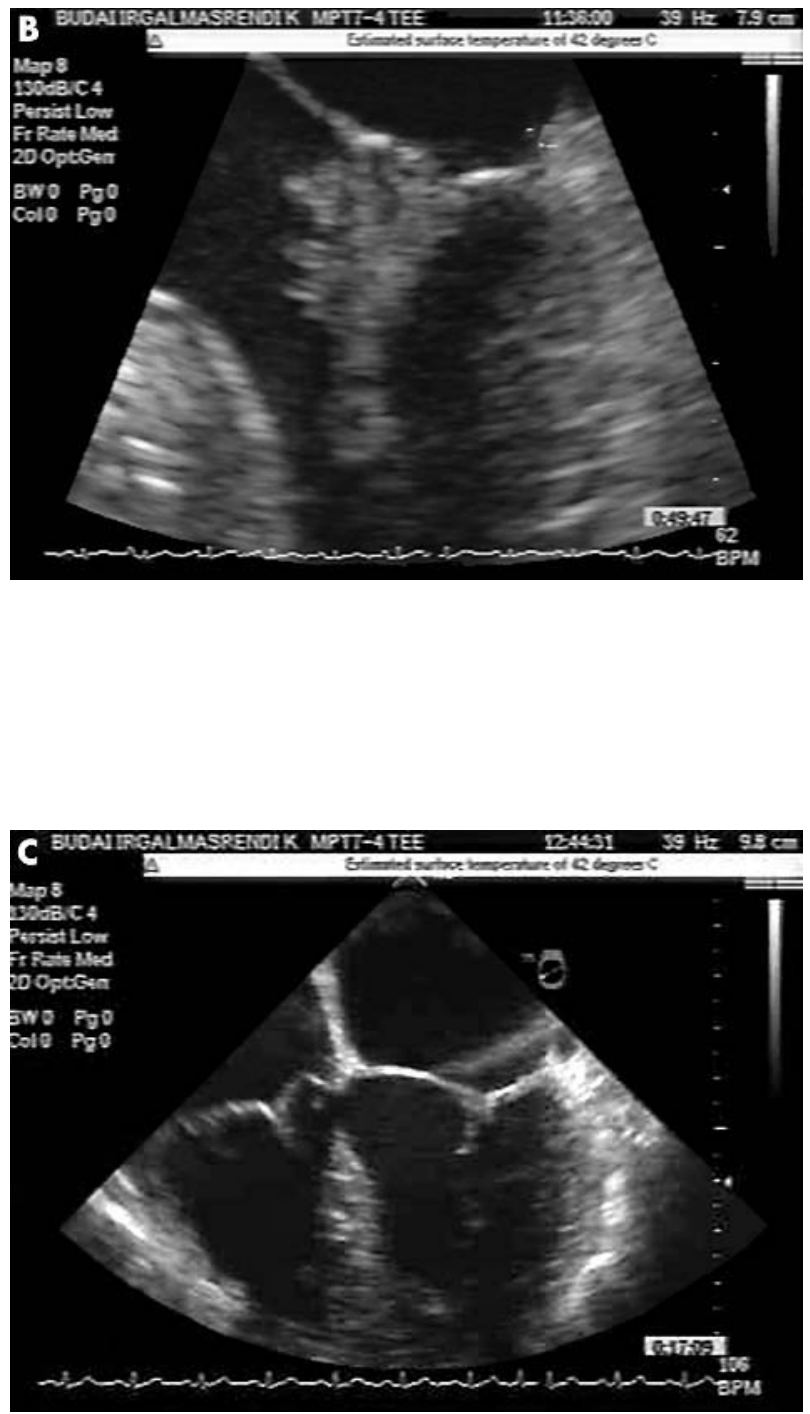